\title{
A Comprehensive Literature Review on Pricing Equity Warrants Using Stochastic Approaches
}

\author{
Siti Zulaiha Ibrahim ${ }^{1, *}$, Teh Raihana Nazirah Roslan ${ }^{2,3}$, Ali F Jameel ${ }^{1}$ \\ ${ }^{1}$ Department of Mathematics \& Statistics, School of Quantitative Sciences, Universiti Utara Malaysia, 06010 Sintok, Kedah, Malaysia \\ ${ }^{2}$ Othman Yeop Abdullah Graduate School of Business, Universiti Utara Malaysia, 50300 Kuala Lumpur, Malaysia \\ ${ }^{3}$ Institute of Strategic Industrial Decision Modelling, School of Quantitative Sciences, Universiti Utara Malaysia, 06010 Sintok, Kedah, \\ Malaysia
}

Received November 18, 2020; Revised May 30, 2021; Accepted June 20, 2021

\section{Cite This Paper in the following Citation Styles}

(a): [1] Siti Zulaiha Ibrahim, Teh Raihana Nazirah Roslan, Ali F Jameel, "A Comprehensive Literature Review on Pricing Equity Warrants Using Stochastic Approaches," Universal Journal of Accounting and Finance, Vol. 9, No. 3, pp. 396 - 404, 2021. DOI: 10.13189/ujaf.2021.090314.

(b): Siti Zulaiha Ibrahim, Teh Raihana Nazirah Roslan, Ali F Jameel (2021). A Comprehensive Literature Review on Pricing Equity Warrants Using Stochastic Approaches. Universal Journal of Accounting and Finance, 9(3), 396 - 404. DOI: 10.13189/ujaf.2021.090314.

Copyright $\odot 2021$ by authors, all rights reserved. Authors agree that this article remains permanently open access under the terms of the Creative Commons Attribution License 4.0 International License

\begin{abstract}
Prior studies revealed that most researchers tend to employ the Black Scholes model to price equity warrants. However, the Black Scholes model was found deficient by contributing to large estimation errors and mispricing of equity warrants. Therefore, issues involving equity warrants are discussed in this paper, by focusing on specific topics and respective stochastic models to provide a basis for improvements in future research. In recent years, stochastic approaches have been used to a great extent among researchers due to the expansive applications in both theoretical and practical sense. Subsequently, this paper provides the results of a comprehensive literature review on various stochastic modelling methods and its applications for pricing financial derivatives in terms of applications, modifications of methods, comparisons with other methods, and general related researches. Focus is given on two types of stochastic models namely stochastic volatility and stochastic interest rate models, along with the discussions associating these two types of models. This paper acts as a valuable source of information for academic researchers and practitioners not only for pricing financial instruments, but also in various other fields involving stochastic techniques.
\end{abstract}

Keywords Equity Warrants, Stochastic Models, Stochastic Volatility, Stochastic Interest Rate, Black Scholes Model

\section{Introduction}

In financial mathematics, the Black Scholes model is a pioneer work by Fischer Black, Myron Scholes and Robert Merton, which is the most widely used model for option pricing. Particularly, the Black Scholes model evaluates the variability of financial instruments over a period of time, and was originally used to estimate the price of European call option which can only be exercised during a certain time period just prior to its expiration. This pricing formula was based on the theory that the stock prices follow a geometric Brownian motion $(\mathrm{gBm})$ with constant drift and volatility. The Black Scholes model is highlighted in this paper since it is protracted from many aspects by other advanced models to describe invariant phenomenon found in real markets. Such extensions include incorporating stochastic interest rates, jumps and many other factors. In this paper, we first briefly describe the stochastic theory and the Black Scholes model, with pertinent facts linking to this model. Section 1 also devotes the formal definitions related to equity warrants, and the revolving issues are reviewed in Section 2. Stochastic interest rates and stochastic volatility form the backbones of Section 3. We discuss the issues on interest rates and volatility in Section 4. In Section 5, we present existing models of stochastic interest rate and stochastic volatility. The last section draws the concluding remarks. 


\subsection{Stochastic Theory}

In 1930s, Aleksandr Khinchin brought the first mathematical description of a stochastic process as the family of random variables indexed by the real line. A stochastic or a random process is generally defined as random variables in probability theory and related areas. Stochastic processes are commonly utilized as mathematical structures and phenomena which seem to differ randomly [1]. Researchers in various areas including computation, engineering, neuroscience, finance and economics are often expected to model real-world situations via stochastic models in order to grasp, evaluate, and infer the random process. Additional studies and examples on applications of stochastic processes may be referred to Gardiner[2]. On the other hand, in finance, stochastic modelling is used as financial models to aid in the decision making of investment, optimization of portfolios, as well as assets and liabilities management. Although mathematically expansive, the stochastic theory has become a subject of great interest due to the various improvement in theories and applications. Some preliminary knowledge of statistical methods are needed to perceive and utilize stochastic processes such as differential equations, recursive relations, geometric series, matrix operations, generating functions, convergence, and conditional expectations [3].

\subsection{The Black Scholes Model}

Stochastic calculus is well-developed in the use of the famous Black Scholes model by predicting the random movements of the asset price. Additionally, this model represents the crucial advancement of theoretical model towards financial sector. The general formula of Black Scholes is presented by

$$
C(S(t), t)=\Phi\left(d_{1}\right) S(t)-e^{-r T} \Phi\left(d_{2}\right),
$$

where $d_{1}=\frac{\ln \left(\frac{S(t)}{X}\right)+\left(r+\frac{\sigma_{S}^{2}}{2}\right)(T-t)}{\sigma_{S} \sqrt{T-t}}, d_{2}=d_{1}-\sigma_{S} \sqrt{T-t}, \quad C$ is the price of call option, $S(t)$ is the stock price at time $t, \Phi$ represents the cumulative normal distribution function, $X$ represents the exercise price, $T-t$ is the time expiration, $\sigma_{S}$ is the standard deviation of the log returns, and $r$ is the rate of interest. Many researchers had proposed extensions to the Black Scholes model from a variety of pricing and hedging instruments. Nevertheless, the accuracy and reliability of Black Scholes model is doubtful, as it follows certain over simplified assumptions such as constant volatility and constant interest rates [4]. Veld [5] claimed that most of the scholars that worked on warrants evoked with this model, and several changes were made to this model to suit the specific warrant features. Despite the fact that the Black Scholes model was well known to investors, it could not be applied to the real-life circumstances [6]. Yet, pricing errors in financial derivatives appeared to be evident. In 2002, Huang and Chen [7] examined the price of covered warrants traded on
12 Taiwan Stock Exchange (TSE) by implementing the Black Scholes model. However, the studies had empirically showed that this model under-priced and overpriced the warrants $[7,8]$. According to [8], this mispricing happened when comparison was made between the prices obtained by the Black Scholes model and the actual market price.

\subsection{Equity Warrants}

In Malaysia, the warrant market is a prominent investment in financial derivative among investors. In year 2015, warrant investment had risen approximately $400 \%$ up to USD 3590.90 million, compared to the year 2014 which only earned USD704.30 million[9]. A warrant is a type of agreement that provides the contract holder the right to purchase or sell an underlying share at a fixed exercise price up to a fixed expiry date. Warrant pricing is very important because traders have to determine the value of each traded product accurately to prevent loses. Moreover, the investors' knowledge about their investment decisions and alternatives are crucial, and these depends heavily on the estimated warrant prices. Xiao et al. [10]stipulated the general equity warrants formula as follows:

$$
W(T)=\frac{1}{N+M k}(k V(T)-N G)^{+},
$$

where $W$ is the value of equity warrant for a firm financed by $N$ common stocks, $M$ is the shares amount for equity warrants outstanding, and $V$ is the present value of underlying asset. When $G$ is paid, the warrant holder will obtain $k$ shares for each warrant at the point of time $T$. Theoretically, warrants and options are very similar, whereby an option is a contract with the dealer or seller of the option [11]. Moreover, the options valuation method might also be associated with warrants, as these two financial derivatives have many similarities [8]. Nonetheless, warrants typically have long maturity period compared to options. It is not surprising that majority of equity warrant issues are still irresolvable due to the intricate nature of warrants pricing [12]. Therefore, researchers in the field of financial derivatives market have focused their attention on creating effective methods for pricing equity warrants.

\section{Possible Issues on Equity Warrants}

We now examine several previously published works in this section. This can help the researchers in understanding the issues of pricing equity warrants. Altogether, we identified eight main issues along with significant findings respectively, as depicted in Table 1. 
Table 1. The equity warrants' issues

\begin{tabular}{|c|c|c|}
\hline $\begin{array}{l}\text { Details of research } \\
\text { information }\end{array}$ & Issues on equity warrants & Significant findings by prior research works \\
\hline $\begin{array}{c}\text { Macbeth and Merville [13], } \\
\text { Veld [5] }\end{array}$ & Pricing biases & $\begin{array}{l}\text { The existence of strike price bias has been confirmed for } \\
\text { options. } \\
\text { Warrants have longer maturity, usually up to } 3 \text { to } 5 \text { years which } \\
\text { complicate warrants valuation. }\end{array}$ \\
\hline $\begin{array}{c}\text { Kim, Yoon, and Yu [14] } \\
\text { Xiao, Zhang, Zhang and Chen } \\
{[15]}\end{array}$ & Constant interest rates & $\begin{array}{l}\text { - Interest rates vary along with random fluctuations over a period } \\
\text { of time. } \\
\text { - Assumption of constant interest rates was clearly inconsistent } \\
\text { with the long lifetime of warrants. }\end{array}$ \\
\hline $\begin{array}{l}\text { Daly [16] } \\
\text { Mitra [6] }\end{array}$ & Constant volatility & $\begin{array}{l}\text { - As the volatility increases, the variable, } \\
\sigma \text {, fluctuates strongly over a certain period. } \\
\text { Black Scholes model induced biased pricing estimates in option } \\
\text { valuation with errors in certain parameters. }\end{array}$ \\
\hline Chang and Liao [17] & Dilution effect & $\begin{array}{l}\text { - Black and Scholes [18] and Galai and Schneller [19] regarded } \\
\text { warrants as options for diluting stocks of the underlying firm. } \\
\text { The correction for dilution was needed because if the dilution } \\
\text { effect is a function of time, pricing errors of dilution adjustment } \\
\text { in pricing models will be greater when the warrants reach the } \\
\text { maturity dates. }\end{array}$ \\
\hline $\begin{array}{c}\text { Ukhov [20] } \\
\text { Bajo and Barbi [21] }\end{array}$ & Unobservable variables & $\begin{array}{l}\text { - The firm's value and variance of the firm for underlying asset } \\
\text { of warrants cannot be directly observed. } \\
\text { The firm may evaluate its current stock price and the stock } \\
\text { volatility estimated from historical prices. } \\
\text { The valuation that involved unobservable parameters is the } \\
\text { most common problem of warrant pricing. }\end{array}$ \\
\hline $\begin{array}{c}\text { Liu [22] } \\
\text { Tian, Yang and Kar [23] }\end{array}$ & Uncertain mean-reverting & $\begin{array}{l}\text { - The experts claimed that the price volatility was not only } \\
\text { affected by randomness but also by the investors' degree of } \\
\text { belief. } \\
\text { The theory of uncertainty should be taken in into account in } \\
\text { modeling indeterminacy. } \\
\text { The basic aspects of uncertainties were randomness and } \\
\text { fuziness. }\end{array}$ \\
\hline $\begin{array}{l}\text { Xiao and Zhang [24] } \\
\text { Kadalbajoo, Kumar and } \\
\text { Tripati [25] }\end{array}$ & Jump-diffusion model & $\begin{array}{l}\text { The model of diffusion could lead to mispricing mainly due to } \\
\text { the fact that the diffusion processes cannot capture the } \\
\text { dynamics of firm behavior. } \\
\text { Jumps can occur at random times, and these jumps cannot be } \\
\text { captured by log normal distribution feature of the stock price in } \\
\text { the Black Scholes model. }\end{array}$ \\
\hline $\begin{array}{c}\text { Misiran [26] } \\
\text { Xiao, Zhang, Xu, \& Zhang } \\
\text { [27] }\end{array}$ & $\begin{array}{l}\text { Fractional Brownian motion } \\
\qquad(\mathrm{fBm})\end{array}$ & $\begin{array}{l}\text { - It is known that } \mathrm{fBm} \text { describes the long memory property or } \\
\text { long-range dependency where this model assist on how to } \\
\text { obtained unknown parameters in stochastic volatility models. } \\
\text { Fractional Brownian motion is not semi-martingale when } \\
\text { actual value of stochastic process does not describe the } \\
\text { probability space. }\end{array}$ \\
\hline
\end{tabular}

As shown in Table 1, the first issue on equity warrants is the potential pricing biases which comprised of warrant strike prices and maturity period. In the Black Scholes model, the striking price bias existed when the forward price was the same as the strike price for at-the-money warrants. At-the-money is a situation when the strike price of an option is identical to the price of the underlying security. This type of bias should be of great significance, since it indicates the possibility of early exercise upon whether the option is in-the-money or out-of-the-money. A call warrant is out-of-the-money when the exercise price exceeds the underlying share price, whereas in-the-money means that the warrant has value in a strike price that is favorable in comparison to the prevailing market price. Apart from that, warrants need to be sold and purchased up to expiration date. If this feature is disregard, these warrants would have to be systematically overpriced or underpriced prior to the exercise date. In the Black Scholes model, short maturity period renders one of the assumptions unworkable as the model only requires short-term call options. Additionally, dilution effect is another issue on warrant pricing which means the devaluation in share prices by virtue of the rising in the number of shares outstanding in a firm relying on new share issuances. The work of [19] introduced the dilution theory that was distribution-free for dilution in the Black Scholes model. The distribution-free is dilution changes can be applied irrespective of the underlying asset price process. This study showed that the increase in the value of a firm was defeated by dilution factor upon warrants exercised. Moreover, [20] investigated that the firm's value and variance of the firm of warrants cannot 
promptly be observed. This is because these dependence structure data cannot be obtained directly from empirical data. Therewith, some pricing models such as Crouhy-Galai's formula and its continuation in [29] that rely on the firm's value presented a downside of dependence on unobservable variables. According to [30], Crouhy-Galai's formula is unlikely to be used since warrants mature concurrently with the debt and thus, a continuation in [29] only emphasized on the potential to exercise at the maturity but also consider a premature exercise possibility at the present time.

Besides that, equity warrants can be evaluated using uncertainty theory of mean-reverting that implies asset valuation and historical returns will gradually regress to long run mean or average level of the whole dataset. The actual financial market is constantly indeterminacy, and we are not permitted to only consider the random factors. Hereby, there are two distinct methods for modelling indeterminacy which are probability theory and uncertainty theory [31]. Further, in modern finance, jump diffusion models which are combined models of jumps and diffusion processes are also used to capture irregular behaviors in asset pricing. Jump diffusion models arise from the assumption that asset returns distribution appear to have heavier tails than normal distributions. Moreover, the volatility smile and leptokurtic feature of the return distribution may be replicated by these types of models. However, existing models including the Black Scholes model do not take these jumps diffusion processes into account and that results in mispricing of the derivatives. The consequence is that the continuous compounded return has a normal distribution which does not comply with leptokurtic feature. Finally, but significantly, as mentioned by [26], fBm portrays the long memory property that supports unknown parameters in stochastic volatility models but has an adverse effect, where it is constant with the Hurst parameter which controls the regularity. Thus, only phenomena with the same irregularities, such as, the age that correlate the shifts in the invariant structure of cardiac variability can be modelled using $\mathrm{fBm}$. Moreover, one of the main features of $\mathrm{fBm}$ is its stationary increments, which can easily be modelled by circulant embedding approach. broadened the model of stochastic volatility driven by $\mathrm{fBm}$ and observed that this model posed a problem in its implementation in terms of estimation of the unknown parameters. Thus, the innovation algorithm and the approach of maximum likelihood estimation were presented to overcome this obstacle.

\section{Stochastic Interest Rates and Stochastic Volatility}

Among all of the issues listed in Table 1, only constant interest rates and constant volatility will be our focal point in this paper, considering that these two issues have been widely documented in the literature as anomalies in the Black Scholes model. This subsection discusses the implementation of stochastic interest rates and stochastic volatility in finance, which acts as a remedy for the discrepancies found in constant interest rates and constant volatility. In recent years, the usage of stochastic interest rates and stochastic volatility has become extremely important to depict financial uncertainty.

\subsection{Stochastic Interest Rates}

Interest rate is a primary determinant of the asset prices and liabilities. Hence, in the field of financial mathematics, the application of stochastic interest rate to the modelling of interest rate and associated derivatives has become more relevant. A review by [14] discovered that the respective models in option pricing did not take completely into account the stochastic factors, since the option pricing model generally have some restricted assumption. They also mentioned that transition in stochastic interest rates may lead to an actual result of option price. For instance, when the real market prices on put and call options were used, the efficiency of the stochastic interest rate was deemed to be more accurate compared to the standard Black Scholes model [32]. Furthermore, [33] who empirically implemented the [34] model to long-term maturity options, found that the pricing errors in the case of stochastic interest rates were smaller compared to the Black Scholes model.

\subsection{Stochastic Volatility}

Volatility is a measure of statistical price fluctuation for a given security during a specific duration [35]. In order to determine the fluctuations in volatility, the alternative model of Heston stochastic volatility was found as being more significant and valid [36]. An early review by [37] had strengthened the Black Scholes' restraint assumption to suit the stochastic volatility in asset returns and had established an empirical option pricing model. Therefore, previous empirical literature indicated that stochastic volatility models of option pricing were better than the Black Scholes model [3].Another interesting and present literature explored that the pricing efficiency was enhanced by integrating stochastic volatility into the Black Scholes model[38]. Furthermore, existing literature also documented that the Hull and White's stochastic volatility model improved warrant pricing [7]. Their experiments obtained the lowest mean absolute error (MAE) and mean absolute percentage error (MAPE) from stochastic volatility with implied volatility, compared to the warrant prices measured by historical volatility. Additionally, scant attention was paid to literature review of stochastic volatility since several authors discovered it was complicated to evaluate options using stochastic 
volatility [7].

\section{Issues on Interest Rates and Volatility}

The complicated nature of problems in constant interest rates and constant volatility were recognized in previous papers, which makes the research more complex. Herewith, in Section 4.1 and 4.2, we develop more sophisticated literature reviews upon the issues on interest rates and volatility.

\subsection{Issues on Interest Rate}

Practically, interest rates vary with random fluctuations eventually, hence the subsequent variability may substantially lead to the price fluctuation behaviour in the volatile market of uncertain interest rate [14]. Nevertheless, the rate of interest typically fluctuating in the real financial market commonly depends on stock market, economy, and national policy. According to [39], dynamics of interest rate are influenced by many aspects, which affects many of all the other financial derivatives that are extremely reactive to it. A review by [40] observed that the assumption of constant interest rate makes the long-lived warrant's evaluation unrealistic in the context of the Black Scholes model. Despite this, investing in assets and liabilities in the financial sector requires interest rate that is not always constant in real world. The increase in mispricing can be related to the invalid assumption of stock price fluctuations, and interest rate being identified as constant over the lifetime of the warrant [41]. Krznaric [42] pointed out that the Black Scholes model had the drawback to the employment of a constant interest rate, since interest rate can change instantly in real markets over a certain duration.

\subsection{Issues on Volatility}

Recent studies reported the capital market liquidity had increased dramatically and this had led to excess volatility of option value [43]. There is an emerging concensus that the greater the variability, the better the variable, $\sigma$, fluctuates over a given period [14]. In the valuation of option pricing, the Black Scholes model created bias estimates, with certain parameters misleading such as constant volatility [6]. In fact, several authors believed that constant volatility could lead to significant mispricing in the evaluation of options with exotic features such as the payoffs, expiration dates and exercise prices which differ from traditional options. Moreover, the problem in warrant pricing was mentioned by [44], regarding the constant volatility assumption that contradicted the reality of the warrant with a maturity of a few years. A review by [45] observed that the pricing errors in the Black Scholes model were greater and escalated as the deep-out-of-the-money were increased by volatility. Kumar and Agrawal [46] also examined the Black Scholes model and the results showed the mispriced options would be extremely high with high volatility of options.

\section{Existing Models of Stochastic Interest Rates and Stochastic Volatility}

In this section, we present some existing models in the literature for pricing financial derivatives, consisting of the pioneer ones and the expanded versions respectively. The pioneer models were sorted by year, along with descriptions regarding the analytical and numerical methods employed in the literature as portrayed in Table 2 below.

Table 2. Numerical and analytical methods of existing stochastic interest rates models

\begin{tabular}{|c|c|c|}
\hline \multicolumn{3}{|c|}{ Stochastic Interest Rate Models } \\
\hline Existing models & Analytical Methods & Numerical \& Simulation Methods \\
\hline $\begin{array}{l}\text { Vasicek Interest Rate Model (1977) } \\
d r(t)=(\eta-\gamma r(t)) d t++\beta d W(t)\end{array}$ & $\begin{array}{l}\text { Vasicek [47], Alobaidi [48], } \\
\text { Jamshidian [49], Mamon [50] }\end{array}$ & \\
\hline $\begin{array}{l}\text { Cox Ingersoll Ross (CIR) Model (1985) } \\
d r(t)=a(b-r(t)) d t+\eta \sqrt{r(t)} d W(t)\end{array}$ & Cox, Ingersoll and Ross [51] & $\begin{array}{l}\text { Chan, Karolyi, Longstaff and Sanders } \\
\text { [52] (Gauss elimination technique) }\end{array}$ \\
\hline $\begin{array}{c}\text { Hull-White (HW) Model (1990) } \\
d r(t)=[\theta(t)+a(t) r(t)] d t+\sigma(t) d W(t)\end{array}$ & Hull and White [53] & Caverhill [54] (Monte Carlo method) \\
\hline $\begin{array}{l}\text { Heath-Jarrow-Morton (HJM) Model (1992) } \\
\qquad d f(t, T)=\alpha(t, T) d t+\sigma(t, T) d W(t)\end{array}$ & $\begin{array}{l}\text { Hull and White [55], } \\
\text { Cox, Ingersoll and Ross [51] }\end{array}$ & $\begin{array}{l}\text { Chan, Karolyi, Longstaff and Sanders } \\
\text { [52] (Gauss elimination technique) }\end{array}$ \\
\hline $\begin{array}{l}\text { London Interbank Offered Rates (LIBOR) (2015) } \\
\qquad d L_{j}(t)=\mu_{j} L_{j}(t) d t+\sigma_{j} L_{j}(t) d W(t)\end{array}$ & & $\begin{array}{l}\text { Andersen and Andreasen [56] } \\
\text { (One-dimensional forward or } \\
\text { backward PDE) }\end{array}$ \\
\hline
\end{tabular}


The Vasicek interest rate model is the first model on the stochastic term structure of rates. The key benefit of the model is that it provides a closed-form formula for bond prices and rates. However, this model permits negative interest rate, which is an immense drawback because this contradicts the reality. Interestingly, [48] observed that this model continues to be popular amongst scholars because it is highly tractable and its closed-form solution can be used for many securities, for example [49] demonstrated how coupons and zero bond are priced under this model. Subsequently, the CIR model develops some improvements to compensate for the deprivation of the Vasicek model. This improvement includes maintaining a positive interest rate that satisfy certain constraints. Nevertheless, it is not easy to solve the stochastic differential equation of the CIR model. As declared by [51], CIR model results in complex pricing formulas for bond prices acquainted with good data fitting for empirical research. Five years ago, the HW model emerged as a future interest rate model, which involves relatively straightforward formulas or methods for pricing derivatives that are commonly traded, for instance, swaptions and caps. Moreover, this model can also precisely reproduce interest rate options on the market [54]. Yet, in the HW model, the interest rates are normally distributed, and this generates a situation where negative rates exist, even if the possibility of this occurring is low.

The following Following this is the HJM model which is implemented to model forward interest rates utilizing differential equation for random events. The main advantage of the HJM-framework is that the yield can be articulated directly in the model as affine functions of short rate. Herewith, exhibited a general multifactor interest rate model compatible with the current interest rate term structure and any defined volatility structure. They found that the HJM model offers valuable insights in theoretical aspects, but it took a considerable time for computations. Besides that, it is very hard to solve the stochastic equation for the spot interest rate as more variables are required in this model. Finally, the LIBOR model is a mechanism of specific interest rates, since it provides a range of hidden forward rates than the short-rate models. The advantage of the LIBOR model is the potential to calibrate via a collection of liquid market instruments while generating a practical evolvement of the forward rate volatility structure. As claimed by [56], the LIBOR market model is being broadened to markets with volatility skews in observable option values. The volatility skews here illustrate the discrepancy between out-of-the-money options, at-the-money option and in-the-money options in implied volatility. These authors reported that the forward rate was expanded to define a specific case for local volatility models to capture smiles and skews. A volatility smile is a graph shape of an implied volatility with the same maturity date for a series of options. Nonetheless, this is not often regarded as an actual advantage over modeling the instantaneous forward rates instantly. The major drawback of the LIBOR model is that the observed implied volatility smile cannot be replicated.

Table 3 below depicts some analytical and numerical methods found in the literature using several existing stochastic volatility models.

Table 3. Numerical and analytical methods of existing stochastic volatility models

\begin{tabular}{|c|c|c|}
\hline \multicolumn{3}{|c|}{ Stochastic Volatility Models } \\
\hline Existing models & Analytical Methods & Numerical \& Simulation Methods \\
\hline $\begin{array}{c}\text { Constant Elasticity of Variance (CEV) Model } \\
\text { (1975) } \\
d S(t)=\mu S(t) d t+\sigma S(t) d W(t)\end{array}$ & & Li, Rong, Zhao and Yi [57] \\
\hline $\begin{array}{l}\text { Generalized Autoregressive Conditional } \\
\text { Heterosdekasticity (GARCH) Model (1982) } \\
d v(t)=\theta(\omega-v(t)) d t+\xi v(t) d W(t)\end{array}$ & Bollerslev [58] & \\
\hline $\begin{array}{c}\text { Heston Model (1993) } \\
d S(t)=r S(t) d t+\sqrt{v(t)} S(t) d W_{1}(t) \\
d v(t)=k(\theta-v(t)) d t+\sigma \sqrt{v(t)} d W_{2}(t)\end{array}$ & Heston [59] & \\
\hline $\begin{array}{c}\text { 3/2 Model (1997) } \\
d v(t)=v(t)(\theta-k v(t)) d t+\xi v(t)^{3 / 2} d W(t)\end{array}$ & Heston [59] & $\begin{array}{c}\text { Ahn and Gao [60] (Finite difference, } \\
\text { Monte Carlo simulation), Carr and Sun } \\
\text { [60] (Finite difference/Finite } \\
\text { element, Monte Carlo simulation), } \\
\text { Baldeaux and Badran [62] (Fourier } \\
\text { inversion and Laplace inversion) }\end{array}$ \\
\hline $\begin{array}{c}\text { Stochastic Alpha Beta Rho (SABR) Model (2002) } \\
\qquad \begin{array}{c}d \mathrm{~F}(\mathrm{t})=\sigma(\mathrm{t})(\mathrm{F}(\mathrm{t}))^{\beta} d \mathrm{~W}(\mathrm{t}) \\
d \sigma(\mathrm{t})=\alpha \sigma(\mathrm{t}) d \mathrm{Z}(\mathrm{t})\end{array}\end{array}$ & $\begin{array}{l}\text { Hagan, Kumar, Lesniewski and } \\
\text { Woodward [63] }\end{array}$ & $\begin{array}{l}\text { Cai, Song and Chen [64] (Laplace } \\
\text { inversion method, Euler method) }\end{array}$ \\
\hline
\end{tabular}


In stochastic volatility models, the CEV model is used to evaluate the value of the risky asset and it has a marked advantage in capturing basic empirical regularities, such as the leverage effect, heteroscedasticity, and the volatility smile. The leverage effect explains the impact of the debt on the return on equity. In addition, heteroscedasticity occurs when the standard deviation of an expected variable, controlled by various independent variable values or as regards preceding period of time are not consistent. According to [57], the CEV model is known as an integral feature of asset price models and it can be regarded as an analysis of the volatility smile and implied volatility. In fact, the efficiency of the CEV model is comparable to most stochastic volatility models, but it is considerably easier to implement and calibrate. Nevertheless, the standard CEV model solution presents high computational efforts as it uses the non-central chi-square approach particularly when the variance's elasticity tends to zero, the volatility is low, or the maturity is small. The next one is Next in line is the GARCH model which is a method of mathematical modeling applied to estimate the return volatility on financial assets. GARCH seeks to reduce estimation errors by addressing errors in previous predictions and increasing the accuracy of current predictions. However, one of the drawbacks is that it is symmetrical in modeling volatility. Additionally, the GARCH model has been improved to include the asymmetrical function of stock volatility. A study by [58] found that the GARCH model generated an eighth order linear decreasing lag structure with slight better fit and more reasonable learning method compared to the ARCH model when an empirical example referring to the uncertainty of the inflation rate was applied.

Moving further, one of the most frequently used stochastic volatility models was initiated by Steven L. Heston in 1993, generally known as Heston model. The model provides its closed-form solution for European call options that can be achieved by call-put parity in the sense of a connection between the volatility process and the spot asset. Heston [59] presented in his paper, a range of verifiable limitations as it applies market biases to spot price dynamics and its distribution. He further observed that the solution technique of the model may be implemented to other problems and is not restricted to stochastic volatility or diffusion issues. Nevertheless, the prices generated by the Heston model are responsive to the parameters, so that the model's fitness will depend on its calibration. Apart from that, the $3 / 2$ model is a non-affine type model with a mean-reverting structure that benefits from the free function of time which contributes more flexibility for model calibration in all maturities. The $3 / 2$ model showed the robust modeling between volatility derivatives and index options [62]. The authors found this model to be successful as upward-sloping implied volatilities in index options can be replicated in contrast to competing model with equal analytical complexity and tractability. Even if it had a qualitative advantage compared to other stochastic volatility models [62], the $3 / 2$ model, or any extension version of this model, has yet to be used to the pricing of equity and VIX derivatives. As importantly, the SABR model illustrates that the implied volatility curve moves in the same direction every time the forward price varies. The benefit of this model is that it does not restrict how negative rates can become, therefore offering a flexible form for adjustment into market data. However, it comes with a notorious weakness where the fact that the probability density function of the forward rate is adverse in very low impacts. A study by [64] explored the ability of exact simulation under SABR model and revealed that its semi-exact simulation scheme even precise when the time period is less than one year. In contrast, the semi-exact simulation triggered bias as the period of time gets longer.

\section{Conclusion}

This paper aims to provide a comprehensive review of existing literature on pricing equity warrants. In this review paper, we first considered the issues of equity warrants. Then, constant interest rates and constant volatility were reviewed specifically as these two issues were our main focal points. From this analysis of review, it is contended that researchers have realized that the standard Black Scholes model could no longer justify the observed interest rates and volatility. A remedial approach led to an extension of the Black Scholes model which involves stochastic interest rates and stochastic volatility. The discussion evolved further into the implementation of stochastic interest rates and stochastic volatility in finance, along with the pioneer models and the expanded ones in terms of the methods applied. This area of inquiry is very essential as it focuses on helping investors and warrant holders to make their investment decisions and trading activities. However, more comprehensive and rigorous work on stochastic models in pricing warrants is needed to justify the usage and application in the finance world.

\section{Acknowledgement}

This research was supported by Ministry of Education (MOE) through Fundamental Research Grant Scheme S/O Code 14193 (FRGS/1/2018/STG06/UUM/02/3).

\section{REFERENCES}

[1] J. Doob. (1990). Stochastic Processes, USA: WILEY Revised Edition. 
[2] C. Gardiner (1997). Handbook of Stochastic Methods for Physics, Chemistry and the Natural, Berlin: Springer-Verlag.

[3] A. L. Wang. (2001). How Much Can Be Taught About Stochastic Process, Training Researchers in the Use of Statistics, pp. 73-85.

[4] W. Wattanatorn. "Beyond Black-Scholes: The Stochastic Volatility Option Pricing Model and Empirical Evidence from Thailand," 2014.

[5] Veld, Chris. "Warrants Pricing: A Review of Empirical Research," The European Journal of Finance, no. 9, pp. 61-91, 2003.

[6] Mitra, Subrata Kumar. "Valuation of nifty options using Black's option pricing model," The European Journal of Finance,, no. 5, pp. 50-91, 2008.

[7] Huang, Yu Chuan and Chen, Shing Chun. "Warrants pricing: Stochastic volatility vs. Black-Scholes," Pacific Basin Finance Journal, no. 10, pp. 394-409, 2002.

[8] Mansor, Nur, Jariah, and Jaffar, Maheran, Mohd. "Black-scholes finite difference modeling in forecasting of call warrant prices in Bursa Malaysia," vol. 1605, no. 1, 2014.

[9] Yip, Y. Y. (2017). The Effects Of Structured Warrants On Firm Performance In Malaysia: The Role Of Institutional Ownership. (Report-Degree of Philosophy).

[10] Xiao, Weilin, Zhang, Weiguo, Xili, Zhang, and Chen, Xiaoyan. "The valuation of equity warrants under the fractional Vasicek process of the short -term interest rate," Physica A: Statistical Mechanics and its Applications, no. 394, pp. 320-337, 2014.

[11] Aziz, Khairu Azlan Abd, Idris, Mohd Fazril Izhar Mohd, Saian, Ridzuan, and Daud, Wan Suhana Wan. "Adaptation of warrant price with black scholes model and historical volatility." AIP Conference Proceeding. no. 1795 (2017).

[12] Londani, Mukhethwa. "Influence of Mathematical Models on Warrant Pricing with Fractional Brownian Motion as Numerical Method." Proceedings 59th $I S I$ World Statistics Congress. (2013): 25-30.

[13] Macbeth, James D. and Merville, Larry J. "Tests of the Black-Scholes and Cox call option valuation models. The Journal of Finance, no. 35 (1980): 285-301.

[14] Kim, Jeong-Hoon, Yoon, Jee-Hun., \& Yu, Seok-Hyon. "Pricing of warrants and the value of the firm." The Journal of Finance, no. 34 (1978): 1333-1342.

[15] Xiao, Weilin, Zhang, Weiguo, Zhang, Xili, and Chen, Xiaoyan. "The valuation of equity warrants under the fractional Vasicek process of the short-term interest rate." Physica A: Statistical Mechanics and its Applications, no. 394 (2014): 320-337.

[16] Daly, Kevin "An overview the determinants determinants of financial volatility: An explanation of measuring techniques." Modern Applied Science, no. 5 (2011): 46.

[17] Chang, Jui-Jane, and Liao, Szu-Lang. "Warrant introduction effects on stock return processes." Applied Financial Economics, no. 20 (2010): 1377-1395.
[18] Black, Fisher, and Scholes, Myron. "The pricing of options and corporate liabilities." Journal of political economy, no. 34 (1973): 637-654.

[19] Galai, Dan, and Schneller, Meir I. "Pricing of warrants and the value of the firm." The Journal of Finance, no. 33 (1978): 1333-1342.

[20] Ukhov, Andrey. "Warrant pricing using observable variables." Journal of Finance Research, no. 27 (2004): 329-339.

[21] Bajo, Emanuele, \& Barbi, Massimilia. "The risk-shifting effect and the value of a warrant". Quantitative Finance, no. 10 (2010): 1203-1213.

[22] Liu, Baoding. "Fuzzy process, hybrid process and uncertain process.” Journal of Uncertain Systems, no. 1 (2008):3-16.

[23] Tian, Miao, Yang, Xiangfeng, and Kar, Samarjit. "Equity warrants pricing problem of mean-reverting model in uncertain environment." Physica A: Statistical Mechanics and its Applications, no. 531 (2019): 121593.

[24] Xiao, Weilin, and Zhang, Xili. "Pricing equity warrants with a promised lowest price in Merton's jump-diffusion model." Physica A: Statistical Mechanics and its Applications, no. 458 (2016): 219-238.

[25] Mohan, Kadalbajoo, Alpesh, Kumar, and Lok, Pati, Tripathi. A radial basis function based implicit-explicit method for option pricing under jump-diffusion models. Applied Numerical Mathematics, no. 110, (2016): 159-173.

[26] Misiran, Masnita. "Maximum likelihood estimation with dynamic measurement errors and application to interest rate modeling." International Journal of Pure and Applied Mathematics, no. 3 (2016): 433-446.

[27] Xiao, Weilin, Zhang, Weiguo, Xu, Weijun, and Zhang, Xili. "The valuation of equity warrants in a fractional Brownian environment." Physica A: Statistical Mechanics and its Applications, no. 4 (2012): 1742-1752.

[28] Geske, Robert and Roll, Richard. "On valuing American call options with the Black-Scholes European formula." The Journal of Finance, no. 2 (1984): 443-455.

[29] [29] Koziol, Christian. "Optimal exercise strategies for corporate warrants." Quantitative Finance, no. 1 (2006): 37-54.

[30] Abínzano, Isabel, and Navas, Javier F. "Pricing levered warrants with dilution using observable variables." Quantitative Finance, no. 8 (2013): 1199-1209.

[31] Zhu, Y. (2019). Uncertain Optimal Control, Singapore: Springer.

[32] Abudy, Menachem and Izhakian, Yehuda. "Pricing stock options with stochastic interest rate." International Journal of Portfolio Analysis and Management, no. (3), (2013): 250-277.

[33] Rindell, Krister. "Pricing of index options when interest rates are stochastic: an empirical test." Jorunal of Banking \& Finance, no. 19 (1995): 785-802.

[34] Amin, Kaushik I, \& Jarrow, Robert A. "Pricing options on risky assets in a stochastic interest rate economy." Mathematical Finance, no. 2 (1992): 217-237. 
[35] Cao, Jiling, Lian, Guanghua, and Roslan, Teh Raihana Nazirah. "Pricing variance swaps using stochastic volatility and stochastic interest rate." no. 277 (2016): 72-81.

[36] Ball, Clifford A, and Roma, Antonio. "Stochastic volatility option pricing." Journal of Financial and Quantitative Analysis, no. 29 (1994): 589-607.

[37] Heston, Steven L. "A closed-form solution for options with stochastic volatility with applications to bond and currency options. Review of Financial Studies, no. 6 (1997): 327-343.

[38] Teng, Long. Ehrhard, Matthias, and Gunther Michael. "Option Pricing with dynamically correlated stochastic interest rate." Acta Mathematica Universitatis Comenianae, 84(2), (2014): 179-190.

[39] Florescu, Ionut, and Veins, Frederi G. "Stochastic volatility: option pricing using a multinomial recombining tree." Applied Mathematical Finance, no. 15 (2008): 151-181.

[40] Lauterbach, Beni, and Schultz, Paul. "Pricing warrants: an empirical study of the black-scholes and its alternatives." The Journal of Finance, no. 45 (1990): 1181-1209.

[41] Kyun, H. B. (2004). Empirical study of Black-Scholes warrant pricing model on the stock exchange of Malaysia. (Research Report-Master of Business Administration)

[42] Krznaric, M. (2016). Comparison of option price from Black-Scholes model to actual values. (Research Projects).

[43] Srivastava, Anubha, and Shastri, Manjula. "A study of relevance of Black-Scholes model on option prices of Indian stock market." International Journal of Governance and Financial Intermediation, no. 1 (2018): 82-104.

[44] Sidenius, Jakob. "Warrant pricing - Is dilution a delusion?" Financial Analysts Journal, no. 52 (1996): 77-80.

[45] Ramazan, Gencay, and Salih, Aslihan. "Degree of mispricing with the Black-Scholes model and nonparametric cures." Economics and Finance. Annals, no. 4 (2003): 73-101.

[46] Kumar, Rajesh, and Agrawal, Rachna. "An empirical investigation of the Black-Scholes call option pricing model with reference to NSE." International Journal of BRIC Business Research, (2017): 1-11.

[47] Vasicek, Oldrich. "An equilibrium characterization of the term structure." Journal of Financial Economics, no. 5 (1977): 177-188.

[48] Alobaidi, Ghada. "A note on bond prices in the Vasicek model." The 2017 WEI International Academic Conference Proceedings, (2017): 79-83

[49] Jamshidian, Farshid. "An exact bond option pricing formula." Journal of Finance, no. 4 (1989): 205-209.

[50] Mamon, Rogemar S. "Three ways to solve for bond prices in the Vasicek model." Journal of Applied Mathematics and Decision Sciences, no. 8 (2004): 1-14.

[51] Cox, John, Ingersoll, Jonathan, \& Ross, Stephen. “A Theory of the Term Structure of Interest Rates. In Theory of Valuation, no. 53 (2005): 129-164.

[52] Chan, K. C., Karolyi, Andrew, Longstaff, Francis A., and Sanders, Anthony. "An empirical comparison of alternative models of the short-term interest rate." The Journal of The American Finance Association, no. 47 (1992): 1209-1227.

[53] Hull, John, and White, Alan. "Pricing interest-rate-derivative securities." Review of Financial Studies, no. 3 (1990): 573-592.

[54] Carverhill, Andrew. "A note on the models of Hull and White for pricing options on the term." The Journal of Fixed Income, no. 5 (1995): 89-96.

[55] Hull, John, and White, Alan. "The general Hull-White model and super calibration." Financial Analysts Journal, no. 57 (2001): 32-43.

[56] [56] Andersen, L, and Andreasen, J. "Volatility skews and extensions of the LIBOR market model." Applied Mathematical Finance, no 1 (2000): 1-32.

[57] Li D., Rong, X., Zhao, H., and Yi, B. "Equilibrium investment strategy for DC pension plan with default risk and return of premiums clauses under CEV model." Insurance: Mathematics and Economics, no 72 (2017): 6-20.

[58] Bollerslev, Tim. "Generalized Autoregressive Conditional Heteroskedasticity." Journal of econometrics, no. 3, 307-327.

[59] Heston, Steven. L. "A closed-form solution for options with stochastic volatility with applications to bond and currency options." Review of Financial Studies, no. 2, 327-343.

[60] Ahn, Dong-Hyun, and Gao, Bin. "A parametric nonlinear model of term structure dynamics." The Review of Financial Studies, no. 12 (1999): 721-762.

[61] Carr, Peter, and Sun, Jian. "A new approach for option pricing under stochastic volatility." Review of Derivatives Research, no. 10 (2007): 87-150.

[62] Baldeaux, Jan, and Badran, Alexander. "Consistent modelling of VIX and equity derivatives using a $3 / 2$ plus jumps model." Applied Mathematical Finance, no. 21 (2013): 299-312.

[63] Hagan, Patrick S., Kumar, Deep, Lesniewski, Andrew, and Woodward, Diana E. "Managing smile risk." The Best of Willmot, no. 1, (2002): 249-296.

[64] Cai, Ning, Song, Yingda, \& Chen, Nan. "Exact simulation of the SABR model." Operations Research, no. 65 (2017): 931-951. 